\title{
Distance Learning During COVID-19 Pandemic in UAE Public Schools: Student Satisfaction, Attitudes and Challenges
}

\author{
Muhammad S Bawa'aneh \\ Ministry of Education, United Arab Emirates \\ Department of Physics, Yarmouk University, Irbid, Jordan \\ ORCID: 0000-0002-1257-1631
}

Received: 21 Nov 2020

Accepted: 6 Mar 2021

\begin{abstract}
In the current circumstances, the second wave of COVID-19 Pandemic is spreading and we seem to have to live longer with most of the urgent measures taken in early 2020 to fight the spread out of the pandemic; of which is school closure. The present study aims at investigating students' satisfaction, attitudes and challenges in UAE public schools during the distance learning time of the third trimester of the academic year 2019-2020. The study also aims to measure differences of satisfaction level, attitudes, and challenges across gender and geographic places of residence within the UAE. Data collection started eight weeks after the commencement of the distance learning process and continued for two weeks. The first eight weeks that preceded data collection witnessed a continuous update of the, previously rich and well established, educational plans in line with continuous development plan for students and instructors that included intensive training for students and instructors on the use of up-to-date educational technologies. That has reflected on the results of the study, where the student satisfaction level, attitudes and challenges were found to lie within the "strong" category indicating high satisfaction level, positive attitude, and minimum faced challenges, with statistically significant differences in the mean across gender and residency for some cases. Such positive result is directly related to the fact that students of the UAE public schools were partially exposed to electronic learning even before the pandemic, the tremendous efforts of the ministry of education to guarantee smooth transfer to full distance learning after the outbreak of the pandemic, and the well established infrastructure of the country.
\end{abstract}

Keywords: student satisfaction, student attitudes, student challenges, distance learning, e-learning, virtual classes, COVID-19

\section{INTRODUCTION}

The unfortunate event of COVID-19 Pandemic outbreak has taken the world by surprise leaving immense impacts on world economy, job markets and particularly on education. To ensure social distancing, lock down measures were taken by governments to many facilities. For academic institutions, the immediate impact of the pandemic in many countries was to adopt the "Schools off Education on" policy to make sure that the educational process is not interrupted during the prolonged school closure. Distance learning was the option to embrace by the majority of countries all over the world; the UAE was not an exception.

Before the pandemic, different academic institutions in different countries were at different levels regarding the adoption of e-learning, if at all. The need and the ability to adapt with the new system of distance learning soon after the outbreak of the pandemic created lots of discussion, cause, and opportunities. Research is one of those opportunities that are now open to discuss challenges and opportunities for best practices in education and fill gaps to ensure the future of education after the pandemic (Pokhrel, 2021). 
UAE students in the various educational institutions may be lucky in the sense that the infrastructure for elearning was established, in part of it, before the pandemic; the Ministry of Education (MoE) in the UAE has provided many platforms and educational resources that are suitable for distance learning. Some are from within the MoE resources and some brought from external sources, which went through a tedious assessment process before adaptation and linking to the Learning Management System (LMS). These include adaptive learning platforms, support educational material that includes interactive technologies, and assessment platforms. Educational plans were reviewed, revised and immediately implemented to suit the new educational method. The LMS was enriched by educational material from several platforms like connectED, Learnetic, ALEKS, Twig, tigtag, together with the existing Emarati platform MADRASA. For virtual labs, the LMS was enriched by virtual labs from Praxilab, PhET and Boclips platforms. Also, the existing agreement with McGraw Hill publishers helped in using their products during the pandemic.

The ministry of education in the UAE was working hard on promoting new educational technologies and teaching pedagogies among teachers and students. Smart teaching and learning was fully supported long before the spread of the pandemic, hence both teacher and student bodies among the MoE had a good level of knowledge and expertise on smart learning. The LMS platform was very rich of educational material from internal and external resources. There were more than one educational material for each section for each chapter for each grade posted on LMS and students and teachers were familiar with online self study using that educational material. Also, extensive training programs were conducted for teachers online (MoE), particularly on conducting virtual labs as a partial substitute for hands - on experiments. That proved vital for a swift transition to full distance learning to go smooth. In this sense, that transition in the UAE may be compared to well off countries and not to some typical less fortunate countries where a vast majority of students are unable to access the internet due to technical as well as monetary issues (Adnan, 2020; Azorin, 2020; Mailizar, 2020; Rose, 2020).

The ministry of education in the UAE was forced by the spread of the COVID-19 Pandemic to fully adopt distance learning by the end of the second trimester for the rest of the academic year 2019-20. As a part of the ongoing blended learning in the UAE public schools, students and teachers were used to accessing educational plans and support material, and conduct a part of their formative exams on LMS, and conduct final summative exams of the third term electronically on Swift Assess. Even though, the whole educational body was overwhelmed by the sudden transfer to full distance learning that took everybody by a surprise; everybody had to learn extra educational technology techniques on a short notice. Everybody was busy with learning how to use Zoom and MS Teams, and instructors were busy in learning new techniques to fully switch to online teaching. Both teachers and instructors had to switch to full online quizzes, assignments, and final exams, and schools' admin and staff were working hard on finding the best ways to manage all that remotely. That added a heavy load on everybody, particularly on students and parents (Bachem et al., 2020).

Since publications concerning education in the time of COVID-19 started to appear in literature, the authors have been noticing that most of the literature have concentrated on higher education institutions in their study of student perspectives on e-learning (Ahmed \& Osman, 2020; lyer et al., 2020) and other subjects like online training in service industry (Tseng \& Chen, 2020). Many of those studies that considered schools tackled teachers rather than students to investigate perspectives, together with other issues like early childhood education, promoting school health education, use of smartphones in e-learning and home environment preparedness (Arturo \& Espinosa, 2021; Milizar, 2020). That was a motive for the authors to try to investigate the student perspectives toward the distance learning process in UAE public schools.

\section{PROBLEM OF THE STUDY}

It was obvious during the first few weeks of the lock down, and the adoption of distance learning following COVID-19 outbreak, that the strong infrastructure within the UAE enabled sustaining a stable internet connection. Also, the strong infrastructure and expertise within the MoE enabled smooth adjustment of learning plans to suit the new situation, swift reaction to enrich the, already rich, LMS with support materials and virtual labs that may partially substitute the hands - on labs experiments, and provide IT support to minimize technical problems. All of that was taking place very smoothly on a high pace. 
The present study aims at trying to assess the above practices by investigating students' perspectives, particularly students' satisfaction, attitude, and challenges during distance learning. We also aim at studying how those three parameters were affected by gender and place of residence within the UAE. The study aims at answering the following six questions;

First Question: What satisfaction level do the students of MoE public schools have toward the adopted procedures and practices in distance learning during COVID-19 outbreak?

Second Question: What attitude do the students of MoE public schools have toward the adopted procedures and practices in distance learning during COVID-19 outbreak?

Third Question: What challenges do the students of MoE public schools face during the adopted distance learning due to COVID-19 outbreak?

Fourth Question: Does the satisfaction of students of MoE public schools with the adopted procedures and practices in distance learning during COVID-19 outbreak vary according to the two variables of gender and residency?

Fifth Question: Does the attitude of students of MoE public schools toward the adopted procedures and practices in distance learning during COVID-19 outbreak vary according to the two variables of gender and residency?

Sixth Question: Do the challenges, students of MoE public schools face during the adaptation of distance learning due to COVID-19 outbreak, vary according to the two variables of gender and residency?

\section{OBJECTIVE OF THE STUDY}

The main objective of our study is to help educators, curriculum and assessment specialists, and decision makers to improve engagement and guarantee smooth content delivery as well as to enhance student performance and motivate positive engagement with distance learning.

The specific objective of the present work is two-fold;

1. measure the satisfaction level, attitude and faced challenges that the students of MoE public schools have toward the adopted procedures and practices in distance learning during COVID-19 outbreak.

2. specify the statistically significant differences in satisfaction level, general attitude and faced challenges of the MoE public schools' students in distance learning during COVID-19 outbreak according to the two variables of gender and residency.

\section{LIMITATIONS OF THE STUDY}

Place: The United Arab Emirates.

Human Frontiers: Students of cycle 3 of public schools of the UAE.

Time Limits: Third term of the academic year of 2019/2020. Term 3 spans over the period of late March to early July 2020, while data collection for this study took place by the end of week 8 and lasted two weeks.

Situational Limitation: The spread of the COVID-19 Pandemic.

\section{OPERATIONAL DEFINITIONS}

Distance Learning: Full online teaching and learning that includes the use of MS Teams as a real-time conference-lesson tool, use of LMS platform of the MoE as an environment for educational plans, self assessment quizzes and homeworks, and finally use of Swift Assess for administering online exams. 
Satisfaction Level: Students' fulfillment of the effectiveness of MoE best practices toward full course delivery during COVID-19 Pandemic, measured by 14 items is the adapted questionnaire.

Attitudes: State of mental readiness of students influenced by their previous experience toward the effectiveness of the use of distance learning during COVID-19 Pandemic outbreak, measured by 5 items in the adapted questionnaire.

Challenges: Difficulties and obstacles that face students during distance learning, measured by 8 items in the adapted questionnaire.

\section{LITERATURE REVIEW}

During the prolonged school closure, which has affected over $90 \%$ of students all around the world, numerous schools, world-wide, have adopted distance learning as a platform to facilitate the teaching and learning process that was done on a short notice. Embracing distance learning by the majority of the educational institutions all around the world brought up the need to research and rethink of best practices to make the learning process as smooth and exciting to students as possible. It has also raised the legitimate question of to what extent should development occurred and benefits gained during the pandemic time be exploited when the situation turns normal? Or even the bigger question of should we ever return to traditional teaching and learning methods (in-school teaching and learning) after the situation has turned normal?

All of that has ignited the spark for research worldwide that aimed at evaluating teaching and learning practices together with evaluating the quick development taking place in industries related to education technology. That provoked numerous studies that aimed at assessment, coming up with conclusions, recommendations, and suggestions on solutions to what may be seen as problems.

In a recent study (Markus, 2020), the author has applied a qualitative method to investigate the learners' perception on online learning in the midst of the COVID-19 Pandemic. His instrument was a structured interview using WhatsApp application after which he conducted a thematic analysis of the interviews. His study does not only show good perception by subject learners but it also sheds light on challenges like the availability of internet access, financial issue and learning implementation. An interesting outcome of his study was the desire of the learners to receive voice notes to explain sent educational material and assignments. Adnan and Anwar (2020) investigated the views and challenges for instructors and students on e-learning implementation during the COVID-19 Pandemic. A major issue that their study highlighted is that desired results cannot be achieved by online learning in underdeveloped countries, where a vast majority of students are unable to access the internet (Adnan \& Anwar, 2020). Using the random sampling technique, Rouadi and Anouti (2020) aimed at studying the online learning experiment in the intermediate and secondary schools in Lebanon during Coronavirus crisis to see if it was a success or a failure. They conducted an online survey on school principals, teachers and students, and reported failure results. They related that mainly to poor teacher abilities and preparation for online teaching, lack of good communication between students and teachers during distance learning, and students' commitment to participate in online classes. In another study, Al Salman et al. (2021) studied students' preferable levels and challenges of using distance learning in COVID-19 of students in Jordanian schools. Their results indicated that the level of students' preferable in using distance learning is medium in general with real learning problems via digital platforms facing students. They also showed no statistically significant differences for the three independent variables of students' gender, educational level and region of residence. Muftahu (2020) explored the implications of the COVID-19 pandemic on higher education by identifying the challenges of sustaining academic programs in developing universities in African context. He found that the Covid-19 pandemic has pushed academic institutions beyond their limits toward developing alternatives to encouraging students to complete their education such as transitioning to remote learning and training of academic staff on the use of online instruction materials and tools. Malkawi and his colleague (2021), Investigated the satisfaction level and attitudes of undergraduate students at United Arab Emirates University towards eLearning during the COVID19 crisis. They found strong student attitudes all across students' gender, educational level, residential 
Table 1. Participants' Distribution Based on the Independent Variables

\begin{tabular}{llccc}
\hline & & Frequency & Percent & Cumulative Percent \\
\hline Gender & Male & 724 & 28.3 & 28.3 \\
& Female & 1835 & 71.7 & 100 \\
& Total & 2559 & & 38.6 \\
\hline Residency & Abu Dhabi & 988 & 38.6 & 100 \\
& Dubai and N. Emirates & 1571 & 61.4 & \\
& Total & 2559 & & \\
\hline
\end{tabular}

location, college, and GPA. They related that positive result to suitable infrastructure and good technical support by the university.

\section{METHODOLOGY AND PROCEDURES}

In the present research descriptive and analytical approach type of study has been used. A survey was sent to all individual students of cycle 3 (Cycle 3 represents grades 9 to 12 with the age range from 15 to 18 years) on their official MoE emails. A week later, a reminder was sent out to those students. We did the statistical analysis of all complete responses for all questionnaire items.

\section{Sample of the Study}

The body of the present study comprised of all cycle 3 students in UAE public schools in term 3 of the academic year 2019/2020. The size of the sample was 2559, of which 724 are males (comprising 28.3\%) and 1835 are females (comprising 71.7\%). Table 1 shows details on the two independent variables, gender and residency, in numbers and percentages. The UAE geo-demography can be divided into two categories, namely Abu Dhabi as one category and Dubai and northern Emirates as the second. From the 2559 students, representing the body of our study, 988 are from the emirate of Abu Dhabi and 1571 from Dubai and northern emirates comprising $38.6 \%$ and $61.4 \%$, respectively.

\section{Questionnaire Validity and Reliability}

A committee of experts, holding PhD degrees in Physics, Methods of Teaching Science, and Education Technology, were invited to test the validity of the questionnaire and give opinion on the clarity, appropriateness and suitability of each item to make sure it meets the goal it is supposed to measure. Adjustments were made according to the experts' feedback, and a revised copy of the questionnaire that included 27 items was put in final form. The 27 items were divided into the following three groups;

- 14 items to measure satisfaction

- 5 items to measure attitude

- 8 items to measure challenges

The items that test "satisfaction" and "attitudes" are designed to mean that the higher the mean $(m)$, the higher the level of satisfaction or attitude, indicating better performance of distance learning. On the other hand, when calculating mean $(m)$ for the "challenges" items, the weight per item is inverted so that higher mean $(m)$ means less challenges, i.e, better distance learning performance.

The researchers calculated the reliability factor by using the Cronbach Alpha equation and reached the overall value of 0.90 . Also, the reliability factor for the first dimension (satisfaction level) was 0.85 , for the second dimension (attitudes) was 0.70 , and for the third dimension (challenges) was 0.77 . These results are considered acceptable for scientific research purposes (Gay et al., 2009). 
Table 2. Mean and SD for satisfaction items ( $N=2559)$

\begin{tabular}{|c|c|c|}
\hline No Items & Mean & Category \\
\hline 1 Distance learning and virtual classes save my time and effort & 5.0438 .83771 & S \\
\hline 2 Distance learning enhances my self-confidence & 5.1079 .81815 & S \\
\hline 3 Distance learning does not restricts my tendency toward critical thinking & 4.9613 .79658 & S \\
\hline 4 I am comfortable doing assignments through distance learning and virtual classes & 5.1192 .82727 & S \\
\hline 5 I trust online exams & 5.1497 .81033 & S \\
\hline $\begin{array}{l}6 \text { Distance learning and virtual classes enhance the } 21^{\text {st }} \text { century skills like critical thinking, problem } \\
\text { solving and cooperation }\end{array}$ & 5.0649 .82362 & S \\
\hline 7 Distance learning helps develop my research and investigation skills & 5.0840 .81256 & S \\
\hline 8 In general, instructors are more supportive during distance learning & 5.1020 .81579 & S \\
\hline $\begin{array}{l}9 \text { Distance learning has enabled me to watch the recorded lessons more than once and helped me } \\
\text { better understand the content }\end{array}$ & 5.1172 .82163 & S \\
\hline $\begin{array}{l}10 \text { Distance learning and virtual classes take into account the diversity among learners (individual } \\
\text { differences, patterns of thinking, motivation, ...) }\end{array}$ & 4.9707 .80819 & S \\
\hline 11 Distance learning does not weaken social ties with friends and colleagues at school & 5.2372 .80095 & S \\
\hline 12 Communication with instructors is not any harder in distance learning than in school learning & 5.2724 .79018 & S \\
\hline 13 I receive the suitable feedback from instructors in distance learning & 5.0516 .81166 & S \\
\hline $\begin{array}{l}14 \text { MoE has provided enough training, clear instructions and reliable platforms for distance learning } \\
\text { environment }\end{array}$ & 4.9609 .80559 & S \\
\hline Overall & 5.0888 & S \\
\hline
\end{tabular}

\section{Statistical Standard}

The survey items are classified into three categories, namely weak (W), medium (M) and strong (S) according to the numerical value of the mean $(m)$ of the individual paragraphs. For paragraph classification, we adopt the following equation (Bawaneh \& Moumene, 2020) to obtain the paragraph class width $P$;

$$
P=\frac{U-L}{N}
$$

where $U$ and $L$ represent the upper and lower limits of the scale, respectively, and $N$ represents the number of required categories. The numerical value of $P$ is obtained by substituting for $U, L$ and $N$ in the above equation. For our study, $P=(6-1) / 3=1.67$. Using the numerical value of $P$, namely $P=1.67$, the three category intervals are determined along the range between 1.00 and 6.00 . They were found to take the following values; $W \in(1.00,2.67), M \in(2.68,4.35)$, and $S \in(4.36,6.00)$, representing weak, medium and strong, respectively. As an example, a paragraph whose mean $(m)$ lies within the range of 4.36 to 6.00 , i.e, satisfies the inequality $(4.36<m<6.00)$ is categorized as $S$, denoting strong (See last column on the right in Tables 2-4).

\section{RESULTS AND DISCUSSIONS}

The first question of this study is "What satisfaction level do the students of MoE public schools have toward the adopted procedures and practices in distance learning during COVID-19 outbreak?". To investigate that, the authors adopted a fourteen - item instrument to measure satisfaction level among the sample learners, where we calculate the mean $(m)$ and the standard deviation (SD). Result is shown in Table 2. The table shows an overall average of 5.0888, which indicates strong overall satisfaction among students of the sample. The highest mean in the table is 5.2724 corresponding to item number 12 indicating that communication with instructors is not that harder in distance learning compared with that in normal school time. The second highest mean, namely 5.2372, corresponds to item number 11 indicating that weakening of social ties among friends and colleagues in the time of the pandemic was not a concern; an issue that is of much concern worldwide, particularly in countries with weak infrastructure for distance learning. On the other end, the lowest mean, namely 4.9609, corresponds to item number 14, once again indicating strong satisfaction among sample students about the measures taken by the MoE regarding providing enough training, clear instruction and reliable platforms for distance learning environment. That is a good point to add to the MoE efforts to minimize difficulties rising at the beginning of the pandemic. Everybody, including students, was still getting familiarized with the available technologies at that early stage of the spread of the pandemic. As 
Table 3. Mean and SD for attitudes' items ( $\mathrm{N}=2559)$

\begin{tabular}{|c|c|c|c|}
\hline No Items & Mean & SD & Category \\
\hline 1 I prefer using e-learning and virtual classes in normal circumstances & 5.1086 & 0.86857 & $\mathrm{~S}$ \\
\hline 2 I enjoy e-learning classes & 5.0500 & 0.84341 & $\mathrm{~S}$ \\
\hline 3 In normal conditions, I prefer e-learning to be a part of the educational plan as a hybrid system & 5.0559 & 0.81402 & $\mathrm{~S}$ \\
\hline 4 In normal circumstances, I don't prefer to go back to the regular learning method at school & 5.1383 & 0.82831 & $S$ \\
\hline $\begin{array}{l}5 \text { I don't need further training programs to help me efficiently use e-learning platform and virtual } \\
\text { classes }\end{array}$ & 5.0825 & 0.80012 & $\mathrm{~S}$ \\
\hline Overall & \multicolumn{2}{|c|}{5.08706} & $S$ \\
\hline
\end{tabular}

seen before in statistical standard calculations (Bawaneh \& Moumene, 2020), a mean that lies within the range between 4.36 and 6 is categorized as strong, hence, the 14 items of Table 2 show strong satisfaction. The findings of Table 2 show that although distance learning made communication with instructors and social ties with colleagues harder compared with that in normal school time, an overall average of 5.0888 indicates high satisfaction which means that students could get over those problems, thanks to MoE tremendous efforts and to the country's good infrastructure. This leads us to conclude that from students' perspective, distance learning was a suitable solution to continue with the learning process while keeping safe. A final point to mention here is that some of the questions of Table $\mathbf{2}$ were rephrased and asked in different ways as a test for the reliability of answers and loyalty of sample members (see for example questions 3 and 6 ). The mean for both categories came out to be very close (Difference in mean was 0.089). That result was a relief for the authors because it indicates good loyalty while filling the survey, i.e, good reliability of results.

The second question of this study is "What attitude do the students of MoE public schools have toward the adopted procedures and practices in distance learning during COVID-19 outbreak?". To investigate this question, we have adopted a five - item instrument to measure attitude level among the sample, where we calculate the mean and the standard deviation (SD). Result is shown in Table 3. The table shows an overall average of 5.0871, which indicates strong overall attitude among students toward distance learning. The highest mean in the table is 5.1382 corresponding to item number 4 indicating good level of preference of distance learning even in normal circumstances. This indicates swift adaptation to distance learning that resulted in such strong interest. The lowest mean is 5.0500 . It corresponds to item number 2 , namely, l enjoy distance learning classes. The difference from the overall mean is 0.0371 ; it is a minor difference and the response still lies within the strong category according to our equation shown in the statistical standard calculations above. Knowing that data was collected by the end of the second month since the distance learning started, such result can be encouraging; it can be taken as an indicator of success for the MoE measures and the country's infrastructure. Some of the questions in Table $\mathbf{3}$ were rephrased and re-asked in different ways as a test for reliability and loyalty purposes (see questions 1 and 4). The mean for both categories came out to be very close (Difference in mean was 0.0297 ). Once again, that result showed good loyalty of the sample and good reliability of results.

The third question of this study is "What challenges do the students of MoE public schools face during the adopted distance learning due to COVID-19 outbreak?". To investigate challenges, we adopted an eight item instrument to measure satisfaction level among the sample, where we calculate the mean and standard deviation (SD). Result is shown in Table 4, where an overall mean of 5.0871 is found that indicates minor challenges. Authors would like to remind the reader that while calculating the mean, weight of each item was inverted so that the higher the mean of an item the less challenges students face. Strongest mean is 5.2704 corresponding to item number 7 , namely, "I do not have my own computer or laptop to use for virtual classes". This should be expected since families are well off and were well prepared for the situation. It may be good here to mention two things; first, the majority of students in public schools belong to Emarati national families with relatively high income, second, most of the shops had good sail on electronic equipment that are used for distance learning soon after the announcement of embracing distance learning by the authorities as the learning method. Those two factors may have helped families secure a device per child in most families, a matter that interprets the strongest mean for item number 7. In Table 3, questions 1 and 7 are very close and were rephrased to be asked in different ways as a test for reliability and loyalty 
Table 4. Means and SD for challenges items $(\mathrm{N}=2559)$

\begin{tabular}{|c|c|c|c|}
\hline No Items & Mean & SD & Category \\
\hline $\begin{array}{l}1 \text { Parents and student family members had to put more effort during the distance learning due to } \\
\text { limited resources like available computers, headphones, etc ... }\end{array}$ & 5.2458 & .80615 & $\mathrm{~S}$ \\
\hline 2 Slow internet consumes my time and weakens my enthusiasm toward distance learning. & 5.1962 & .81510 & $\mathrm{~S}$ \\
\hline 3 Continuous interruption in internet weakens communication with my teachers & 5.2157 & .81063 & S \\
\hline 4 I had to pay more money to upgrade internet speed due to distance learning & 5.0731 & .79907 & $\mathrm{~S}$ \\
\hline 5 I face difficulty in accessing tasks assigned by the teacher online & 4.9816 & .80317 & $\mathrm{~S}$ \\
\hline 6 I very often get distracted by adverts and browsing other sites during e-learning & 5.0817 & .80361 & $\mathrm{~S}$ \\
\hline 7 I don't have my own computer or laptop to use for virtual classes & 5.2704 & .75052 & $\mathrm{~S}$ \\
\hline 8 Distance learning was not a satisfying solution for practical parts of the educational material & 5.2435 & .80444 & $\mathrm{~S}$ \\
\hline (Overall) & \multicolumn{2}{|c|}{5.1635} & $\mathrm{~S}$ \\
\hline
\end{tabular}

Table 5. Descriptive statistics for student satisfaction according to gender and residency

\begin{tabular}{llccc}
\hline & & Number & Mean & SD \\
\hline Gender & Male & 724 & 5.1089 & 0.49296 \\
& Female & 1835 & 5.0808 & 0.46392 \\
& Total & 2559 & 5.0888 & 0.47239 \\
\hline Residency & Abu Dhabi & 988 & 5.1050 & 0.50199 \\
& Dubai and N. Emirates & 1571 & 5.0785 & 0.45265 \\
& Total & 2559 & 5.0888 & 0.47239 \\
\hline
\end{tabular}

Table 6. ANOVA analysis for satisfaction

\begin{tabular}{llccccc}
\hline & & Sum of squares & $\mathrm{df}$ & Mean square & F-test & Significance \\
\hline Gender & Between groups & 0.410 & 1 & 0.410 & 1.839 & 0.175 \\
& Within groups & 570.408 & 2557 & 0.223 & & \\
& Total & 570.818 & 2558 & & & \\
\hline Residency & Between groups & .427 & 1 & 0.427 & 1.913 & 0.167 \\
& Within groups & 570.391 & 2557 & 0.223 & & \\
& Total & 570.818 & 2558 & & & \\
\hline
\end{tabular}

matters. The mean for the two categories is very close, and the difference in mean was 0.0246 showing good loyalty and reliability.

The fourth Question of our study is "Does the satisfaction of students of MoE public schools with the adopted procedures and practices in distance learning during COVID-19 outbreak vary according to the two variables of gender and residency?". To answer the question, we calculated the mean and SD associated with the two independent variables of gender and residency. Results are presented in Table 5. As far as gender is concerned, results show minor difference in mean $(m)$ between males (mean $=5.1089$ and SD $=0.49296$ ) and females (mean $=5.0808$ and $S D=0.46392)$. As for satisfaction dependence on residency, results show satisfaction level of a mean of 5.1050 (SD = 0.50199) for students of Abu Dhabi and of $5.0785(S D=0.45265)$ for Dubai and northern Emirates, which, once again, indicates minor difference.

As a test for the validity of results of Table 5, we performed the ANOVA analysis with results presented in Table 6. Results show no statistically significant differences for the two independent variables $(\alpha<0.05)$; significance takes the values of $0.175(F=1.839)$ and $0.167(F=1.913)$ for gender and residency variables, respectively, indicating high satisfaction across gender and residency. MoE effort is distinguished here with no difference across gender or geography, as all public schools are of the same importance for authorities in providing services with no preferences.

The fifth Question of our study is "Does the attitude of students of MoE public schools toward the adopted procedures and practices in distance learning during COVID-19 outbreak vary according to the two variables of gender and residency?". As done with satisfaction, to answer the question we calculated the mean and SD associated with the two independent variables of gender and residency. Results are presented in Table 7. For gender, results show a higher mean among males (mean $=5.1494$ and $S D=0.56051$ ) compared to that among females (mean $=5.0625$ and SD $=0.54790$ ). For residency, results show a higher mean for Abu Dhabi (mean 
Table 7. Descriptive statistics for student attitude according to gender and residency

\begin{tabular}{llccc}
\hline & & Number & Mean & SD \\
\hline Gender & Male & 724 & 5.1494 & 0.56051 \\
& Female & 1835 & 5.0625 & 0.54790 \\
& Total & 2559 & 5.0871 & 0.55278 \\
\hline Residency & Abu Dhabi & 988 & 5.1190 & 0.57196 \\
& Dubai and N. Emirates & 1571 & 5.0670 & 0.53959 \\
& Total & 2559 & 5.0871 & 0.55278 \\
\hline
\end{tabular}

Table 8. ANOVA analysis for attitude

\begin{tabular}{llccccc}
\hline & & Sum of squares & $\mathrm{df}$ & Mean square & F-test & Significance \\
\hline Gender & Between groups & 3.929 & 1 & 3.929 & 12.918 & 0.000 \\
& Within groups & 777.713 & 2557 & 0.304 & & \\
& Total & 781.642 & 2558 & & & \\
\hline Residency & Between groups & 1.644 & 1 & 1.644 & 5.390 & 0.020 \\
& Within groups & 799.998 & 2557 & 0.305 & & \\
& Total & 781.642 & 2558 & & & \\
& & & & &
\end{tabular}

Table 9. Descriptive statistics for student challenges according to gender and residency

\begin{tabular}{llccc}
\hline & & Number & Mean & SD \\
\hline Gender & Male & 724 & 5.1602 & 0.52250 \\
& Female & 1835 & 5.1648 & 0.47976 \\
& Total & 2559 & 5.1635 & 0.49213 \\
\hline Residency & Abu Dhabi & 988 & 5.1905 & 0.50067 \\
& Dubai and N. Emirates & 1571 & 5.1465 & 0.48607 \\
& Total & 2559 & 5.1635 & 0.49213 \\
\hline
\end{tabular}

$=5.1190$ and $\mathrm{SD}=0.57196)$ compared with that for Dubai and northern Emirates (mean $=5.0670$ and $\mathrm{SD}=$ 0.53959).

We now perform the ANOVA analysis to test the validity of results of Table 7. ANOVA test results are presented in Table 8. They show statistically significant difference for the two independent variables ( $\alpha<$ $0.05)$; significance $=0.000(\mathrm{~F}=12.918)$ and $0.020(\mathrm{~F}=5.390)$ for gender and residency variables, respectively. For the significant difference across gender, males show better attitude toward distance learning, which may have given them the freedom to attend classes in the bedroom, the garden or even a café, hence a favourable method of education. Females, on the other hand, turned out to be more conservative in that sense and showed more commitment to attending classes at school. As for the significant difference for residency, higher attitude mean $(m)$ for Abu Dhabi students may be linked with better facilities at home since all emirates have equally good infrastructure compared to many countries in the region. However, Abu Dhabi may still have better infrastructure. Also, families in Abu Dhabi may be more capable for providing children with better learning conditions at home.

The sixth Question of our study is "Do the challenges, students of MoE public schools face during the adoption of distance learning during COVID-19 outbreak, vary according to the two variables of gender and residency?". To answer the question, the authors present descriptive statistics for student challenges according to gender and residency. The mean and SD associated with the two independent variables of gender and residency are presented in Table 9. Results show mean $=5.1602$ and SD $=0.52250$ for males, and mean $=5.1648$ and SD $=0.47976$ for females, where a minor difference of 0.0046 is found between males and females. As far as residency is concerned, the mean for Abu Dhabi was found to be 5.1905 (SD = 0.50067), while that for Dubai and northern was found to be 5.1465 (SD = 0.48607). The difference is 0.044 .

ANOVA analysis for testing the validity of results of Table 9 is presented in Table 10. Results show no statistically significant difference for gender (significance $=0.833, F=0.045$ ). No discrimination between allgirl schools and all-boy schools regarding distribution of facilities, infrastructure and training interprets the result. A statistically significant difference for residency was found (significance $=0.027$ and $F=4.868$ ), with Abu Dhabi students feeling less faced challenges. This may indicate better infrastructure and better family 
Table 10. ANOVA analysis for challenges

\begin{tabular}{llccccc}
\hline & & Sum of squares & $\mathrm{df}$ & Mean square & F-test & Significance \\
\hline Gender & Between groups & 0.011 & 1 & 0.011 & 0.045 & 0.833 \\
& Within groups & 619.510 & 2557 & 0.242 & & \\
& Total & 619.521 & 2558 & & & \\
\hline Residency & Between groups & 1.177 & 1 & 1.177 & 4.868 & 0.027 \\
& Within groups & 618.344 & 2557 & 0.242 & & \\
& Total & 619.521 & 2558 & & & \\
\hline
\end{tabular}

preparedness for distance learning at home. As far as residency is concerned, results of ANOVA analysis for challenges coincide with that for attitude in favoring Abu Dhabi students on those of other emirates in having a better attitude and feeling less challenges regarding distance learning.

\section{SUMMARY, CONCLUSIONS, AND RECOMMENDATIONS}

The current study aims at investigating students' perspectives toward distance learning adopted as a result of the spread out of COVID-19 Pandemic. To achieve that goal, student satisfaction, attitudes and challenges in UAE public schools during the distance learning time of the third trimester of the academic year 2019-2020 were studied through a survey sent to students of cycle three of UAE public schools on their individual MoE emails, where data was collected eight weeks after the commencement of the distance learning process and continued for two weeks. As mentioned in the introduction, the first eight weeks of distance learning before collecting the data witnessed extended efforts by the MoE curriculum and assessment sector in continuously updating educational plans and continuously conducting training sessions for students and instructors on how to better use available educational platforms. The sample of our study consists of 2559 students. $28.3 \%$ of the surveyed students were males, while $71.7 \%$ were females. Also, $38.6 \%$ come from Abu Dhabi and 61.4\% from Dubai and Northern Emirates. The survey items can be classified into three groups that measure satisfaction, attitude and challenges.

The overall results of the present study show strong student satisfaction, positive attitudes and minor challenges. That may be interpreted as a direct result of the well preparedness of the MoE and the well established infrastructure of the country as a whole.

Tables 2, 5, and $\mathbf{6}$ show results related to satisfaction level. The overall mean for all survey items of Table $\mathbf{2}$ is 5.0888 indicating strong category. The highest and lowest means are 5.2372 and 4.9609 , respectively, with both being within the strong category, i.e., all items are categorized as strong. Descriptive statistics for student satisfaction according to gender and residency is shown in Table 5. Related ANOVA analysis shown in Table 6 presents insignificant differences in satisfaction level between genders or residency. We attributed high satisfaction level to two main factors; the strong electronic infrastructure of the country compared to many other countries within the region and beyond, and to strong infrastructure in the MoE regarding the existence of well - developed educational platforms and the tremendous effort of the MoE focused on facilitating that infrastructure for students and instructors and the swift implementation of an emergency training plan that started with the set off of distance learning.

Tables 3, 7 and $\mathbf{8}$ show results related to student attitude level. In Table $\mathbf{3}$ an overall mean of 5.0871, categorized as strong, is found. The highest and lowest means are 5.1382 and 5.0500, respectively, with statistically significant difference in attitude across genders favouring males. This result shows more loyalty among females to traditional school learning, while males have more tendency toward preference of having classes virtually. This can be best related to social emotional issues related to the feeling of missing school and colleagues, in the early stages of pandemic spread when lock down policy was implemented, being stronger among females. Results also show statistically significant difference in attitude regarding residency, with the Abu Dhabi students showing better attitude to distance learning; a result that may indicate better facilities (better accommodation and internet connection at home wise) that enable students to accommodate with distance learning in a better way compared to their peers in the northern Emirates. 
Tables 4, 9 and $\mathbf{1 0}$ show results related to faced challenges. The overall mean for all survey items of Table $\mathbf{4}$ is 5.0871 , i.e., strong category. All items show means within the strong category, indicating minor challenges. As an interpretation of this result, we may say that although the whole educational body in the world was taken by the pandemic by surprise that should reflect worries among students and probably among instructors and parents, the MoE public schools had a good infrastructure and students were partially used to the e-learning environment through using LMS as an interactive platform with teachers. That has put relatively less challenges ahead of them in the early stages of implementing full distance learning after the spread of the pandemic. Results also show statistically significant difference for residency (significance $=$ 0.027 and $F=4.868$ ), with Abu Dhabi students showing less challenges. The result may be linked to better infrastructure in Abu Dhabi at least on the family level, since schools across the country have the same level of infrastructure and facilities. No statistically significant difference across gender was found.

High satisfaction level, good attitude, and minimal significant challenges lead the authors to recommend sustaining the good level of adoption of modern educational technology facilities, that the MoE adopted before the pandemic outbreak and accelerated since the beginning of distance learning. A recommendation for a further study may be to thoroughly investigate platforms and facilities in terms of structure and use by students and teachers. The perspectives of teachers and parents may also be a good recommendation for a future study. A point of further discussion can be the student preference of distance learning even after the situation turns back to normal. In this matter we may suggest that a hybrid educational system may be the best model for the future of education after COVID-19, so that we keep the expertise we gained and be prepared for any future similar crises. For that to be achieved, we need to redesign and restructure the content according to modern theories of educational technology.

Lack of previous studies on attitudes of school students in the UAE, and to a lesser degree in the region and beyond (Al Salman et al., 2021), was the main motive for the current study. Comparison with the very few studies show higher student satisfaction level among UAE public school students compared to their peers in other countries. The explanation of such result is directly related to two elements; first one is the preparedness of the educational system and the familiarity of students and teachers with online teaching before the outbreak of the pandemic made students digest the idea of distance learning once implemented. The second reason is, as explained throughout the text, the swift measures taken by the Ministry of Education soon after the outbreak of the pandemic that includes training programs and implementation of extra educational resources on LMS. Results of a previous study on UAE University students' attitudes toward distance learning Malkawi and his colleague (2021) shows high student attitudes; similar interpretation was given for the high level of student satisfaction. Meanwhile a similar study of student satisfaction of science students at Imam Abdulrahman Bin Faisal University, Saudi Arabia (Bawaneh, 2021), showed less levels of satisfaction.

As a final remark, the authors would like to add their opinion in the answering of the big question raised in the first paragraph of the literature review of should we return to traditional method of in-school teaching and learning after the pandemic is over. We believe we should for the several obvious reasons of going back to full, socially active educational process, where the physical class is the playground for all innovative educational methods to apply, and where children fully socialize through curricular group teamwork and during breaks. We should go back to classroom where a good teacher is a true inspirer, and where the body language and eye contact during classes, that are missed with distance learning, best convey the full message. We need to go back to classroom, but we need to carry with us all gained benefits and all expertise we have worked hard to achieve during this difficult time that we wish to end soon. Those gained benefits and expertise, together with the vast development in educational technology that is taking place in a short time, enable the educational body worldwide to take education to the next level of best manipulation of available resources and best use of achievements for better education of the next generation.

Funding: The author received no financial support for the research and/or authorship of this article.

Declaration of interest: Author declares no competing interest.

Data availability: Data generated or analysed during this study are available from the author on request. 


\section{REFERENCES}

Adnan, M., \& Anwar, K. (2020). Online learning amid the COVID-19 pandemic: Students' perspectives. Journal of Pedagogical Sociology and Psychology, 2(1), 45-51. https://doi.org/10.33902/JPSP.2020261309

Ahmed, A., \& Osman, M. (2020). The Effectiveness of Using Wiziq Interaction Platform on Students' Achievement, Motivation, and Attitudes. Turkish Online Journal of Distance Education-TOJDE, 21(1), 19-30. https://doi.org/10.17718/tojde.690112

Al Salman, S., Alkathiri, M., \& Bawaneh, A. (2021). School off, learning on: identification of preference and challenges among school students towards distance learning during COVID19 outbreak. International Journal of Lifelong Education, Published online: 3 February 2021. https://doi.org/10.1080/02601370.2021.1874554

Arturo, G., \& Espinosa-Ramos, E. (2021), Addiction to the Smartphone in High School Students: How It's in Daily Life?. Contemporary Educational Technology, 13(2), ep296. https://doi.org/10.30935/cedtech/9609

Azorin, C. (2020). Beyond COVID-19 supernova. Is another education coming?. Journal of Professional Capital and Community, 5(3|4), 381-390. https://doi.org/10.1108/JPCC-05-2020-0019

Bachem, R., Tsur, N., Levin, Y., Abu-Raiya, H., \& Maercker, A. (2020). Negative Affect, Fatalism, and Perceived Institutional Betrayal in Times of the Coronavirus Pandemic: A Cross-Cultural Investigation of Control Beliefs. Frontiers in Psychiatry, 589914, 10.3389/fpsyt.2020.589914. https://doi.org/10.3389/fpsyt.2020.589914

Bawaneh, A. (2021). The Satisfaction Level of Undergraduate Science Students Towards Using E-Learning and Virtual Classes in Exceptional Condition Covid-19 Crisis. Turkish Online Journal of Distance EducationTOJDE, 22(1), 52-65. https://doi.org/10.17718/tojde.849882

Bawaneh, A. K., Moumene, A. B. H., \& Aldalalah, O. (2020). Gauging the Level of Reflective Teaching Practices among Science Teachers. International Journal of Instruction, 13(1), 695-712. https://doi.org/10.29333/iji.2020.13145a.

Gay, L. R., \& Airasian, P. W. (2003). Educational research: Competencies for analysis and application (7th Ed), Prentice-Hall.

Iyer, P., Aziz, K., \& Ojcius, D. M. (2020). Impact of COVID-19 on dental education in the United States. Journal of Dental Education, 84, 718-722. https://doi.org/10.1002/jdd.12163

Mailizar, Almanthari, A., Maulina, S., \& Bruce, S. (2020). Secondary School Mathematics Teachers' Views on E-learning Implementation Barriers during the COVID-19 Pandemic: The Case of Indonesia. EURASIA Journal of Mathematics, Science and Technology Education, 16(7), em1860. https://doi.org/10.29333/ejmste/8240

Malkawi, E., Bawaneh, A., \& Bawa'aneh, M. S. (2021). Campus off, Education on: UAEU Students' Satisfaction and Attitudes Towards E-Learning and Virtual Classes During COVID 19 Pandemic. Contemporary Educational Technology, 13(1), ep283. https://doi.org/10.30935/cedtech/8708

Markus, D. (2020). Is the online learning good in the midst of Covid-19 Pandemic? The case of EFL learners. Journal Sinestesia, 10(1), 1-10.

Pokhrel, S., \& Chhetri, R. (2021). A Literature Review on Impact of COVID-19 Pandemic on Teaching and Learning. Higher Education for the Future, 8(1) 133-141. https://doi.org/10.1177/2347631120983481

Rose, S. (2020). Medical Student Education in the Time of COVID-19. Journal of American Medical Association, 323(21), 2131-2132. https://doi.org/10.1001/jama.2020.5227 
Rouadi, N., \& Anouti, M. F. (2020). The Online Learning Experiment in the Intermediate and Secondary Schools in Lebanon During the Coronavirus Crisis. International Journal of Advanced Research in Science, Engineering and Technology, 7(7), 14466-14485.

Tseng, C., \& Chen, T. (2020). Impact of Web-Based Teaching on the Learning Performance of Education and Training in the Service Industry during COVID-19. Contemporary Educational Technology, 12(2), ep277. https://doi.org/10.30935/cedtech/8581

Correspondence: Muhammad S Bawa'aneh, Ministry of Education, United Arab Emirates and Department of Physics, Yarmouk University, Irbid, Jordan. E-mail: msbawaaneh@yu.edu.jo 